\title{
System to Prevent Helmet Theft and Wireless Monitoring of Health Status of the Bike
}

\author{
Ayush Kr. Mittal \\ B.Tech Scholar (final year) \\ Department of E.C.E \\ Graphic Era University, \\ Dehradun, Uttarakhand, India
}

\author{
Anamika Bhatia, PhD. \\ Head Department of ECE \\ Graphic Era University, \\ Dehradun,Uttarakhand \\ India
}

\author{
Abhishek Kumar Mittal \\ Department of C.S.E Quantam \\ School of Technology, \\ Roorkee, Uttarakhand, India
}

\begin{abstract}
The use of helmet is compulsory for any bike driver for his safety. When one is going towards office or its destination, he carries the helmet, after parking it in a parking lot, often these helmets are stolen from the parking lot. A low cost anti theft scheme has been proposed based on microcontroller and GSM (Global system for Mobile communication) module which will generate an alarm on account of any suspicious activity. Beside this, maintenance routine of the bike is continuously monitored by the system, important updates like engine oil condition, odometer reading and other useful data available in digital format is monitored for a headache free experience. This feature has been demonstrated by a prototype model.
\end{abstract}

\section{Keywords}

microcontroller, anti - theft, low cost, helmets, bikes, maintenance .

\section{INTRODUCTION}

One of the reasons why people avoid wearing helmet may be the problem of handling/storing. It is very frustrating and irritating when one return from a mall or party and finds that the helmet missing from the bike, some burglar had stolen it by cutting its strap. The helmet lock is of no use at that moment. At some places there is provision for storing your helmets but at most places you have to carry it with yourself. It is often seen that people carry their helmets along with them. Now a days following types of helmets are available in the market Full face, Off-road / motocross, Modular or "flip-up", Open face or 3/4 helmet, Half helmet [1][2]. All these helmets are different in design and have different standards of security. But all of them have a common thing i.e. a strap. A strap is used to tighten the helmet around the head, it is tied across the chin. The main objective of the present work is to develop a low cost technology for helmets to prevent them from theft and also to monitor any kind of suspicious activity around the bike and helmet. With the word suspicious activity it means that if someone tries to touch or try to move the helmet away from the bike an alarm will be set ON. The system has two types of alarms, first is the voice alarm to attract the security guard at the parking lot and other is a Short text message send to the owner of the bike with the help of a GSM [3] (Global System for mobile communication) module attached. The purpose of attaching the GSM module is not only to send a short message to the owner, on account of suspicious activity. But GSM module is also used to monitor the health status of the bike. With the word 'health status' it means that, the engine oil condition, battery health, engine health and service remainder of the bike is being monitored continuously by the system. On account of, detection of any fault in the bike, it can be immediately notified to the owner by sending a short message on the mobile. As if the battery condition is not good, information regarding the battery is sent to the owner. In this system the entire condition of the bike is being monitored wirelessly. Other features like regular remainders on the service of the bike can also be sent to the owner. The system is proposed using 8 bit microcontroller of AVR family (Atmel ATmega 16) [4], a GSM module with little modification in the design of the helmet.

\section{SYSTEM STRUCTURE AND WORKING}

\subsection{For protection from theft}

The main aim is to generate an alarm, when any suspicious activity is detected by the external environment. A microcontroller is fixed under the vehicle seat, embedded on the PCB (Printed circuit board). The PCB draws a negligible amount of current, so the entire power to run the circuit is taken by the battery of the bike. Inside the helmet core, a electric wire is inserted through the strap making a loop such that wire goes throughout the whole core via the strap and after going through the core it comes out through that same strap. Special consideration is taken that no security features of the helmet are hampered [5][6].

A helmet with a strap is shown in Fig.1. Inside the strap a red colour line depicts the electrical wire inserted inside. This wire after travelling through the core of the helmet returns out of the same strap. This makes an electrical loop. A connector is provided in the 


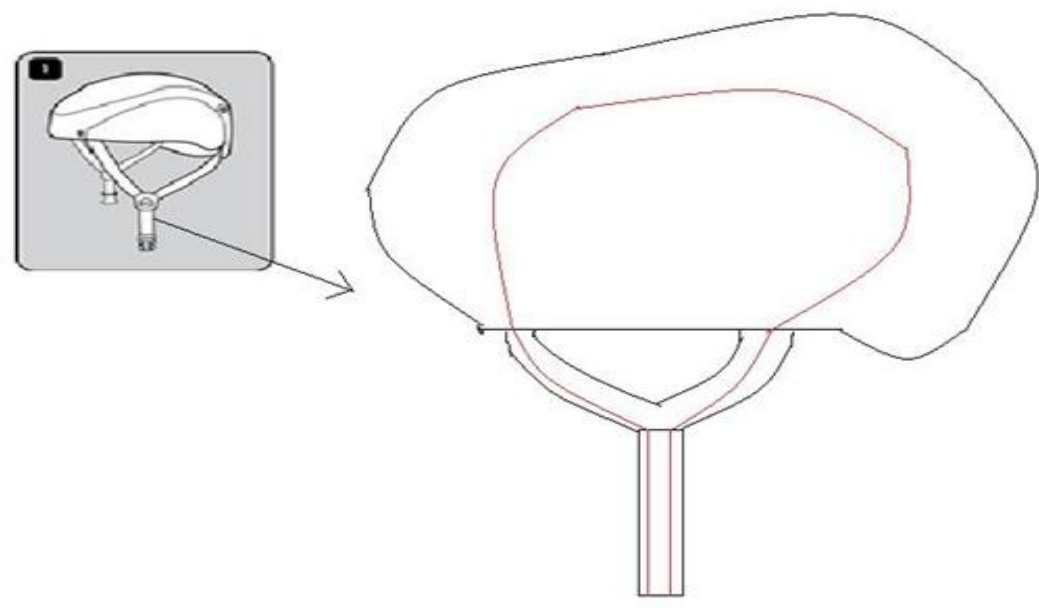

Fig 1: Modification in Helmet

bike in which two pins of the microcontroller are connected. The strap will be inserted inside the connecter in such a manner that electrical conduction will take place between the wire embedded inside the strap and the two pins inside the connecter. A signal is sent from the microcontroller to one of the pins of the connecter, which is then transmitted through the wire inside the helmet, along its strap, and then the signal after going around through the helmet, signal is received on the other pin of the connecter and reaches the microcontroller. The system in an active state is continuously sending signals and those signals are also being received by the controller. But when someone cuts the strap, the sent signal is lost and no signal is received then, the microcontroller will switch on a relay which will drive a piezo speaker/horn[7]. Hence gaining attraction of security at the site of theft and will also activate the GSM module which will send the message to the owner of the bike. The system actually works on connectivity principle, when the helmet is at proper place there is connectivity but when someone cuts the strap down connectivity is lost, which could be sensed by the controller.

\subsection{For the health status of the bike}

In the former section, a scheme has been discussed which can be used to protect helmets from getting stolen. Now in this section, the monitoring of health status is discussed. As described earlier, health status means that the condition of bike at that moment of time. In a motor vehicle, various conditions need to be checked, conditions like engine oil condition, battery health, engine health and service remainder of the bike. In most of the modern bikes instead of an analogue meter to determine such conditions, a digital meter is employed. With the help of a digital meter all such data is available in digital format, hence to send this data to the user is an easy task through the GSM module. The advantage of using such a system is that, one can easily access all the data regarding the health status of the bike without going to any mechanic. In the programming section certain threshold values are selected to check the engine oil condition, battery health and engine health, if the digital values of these variable exceeds a particular value of threshold, than the alert is sent to the user using the GSM module else if the values are at innocuous levels (below the threshold level) no alarm is sent to the owner. The threshold values can be different for different bikes and can be set in the programming section after consulting the manufacturers of the bikes.

The monitoring of health status with the help of GMS module will help fast moving city dwellers to have a check on their motor bikes with an ease. Hence, a tension free environment is created for the owners regarding their bikes after installing the above mentioned system.

\section{HARDWARE USED}

\subsection{Power supply}

First of all we have to design a constant 5V DC (Direct Current) supply to power our microcontroller, the main source of the power is taken from the battery of the bike. It is of $12 \mathrm{~V}$, and hence it is easy to construct a standard 5V DC supply.

\subsection{Microcontroller}

"Atmel Atmega16 microcontroller" [4] is used for the proposed application. As the code is very small i.e. less than $1 \mathrm{~KB}$, "Atmel ATiny"[8] series microcontroller are best for this application due to their small size and very less power consumption. But Atmega 16 
microcontroller

in the prototype is used to demonstrate the working.

\subsection{Special modification}

Some special modifications are required to be done in the design of helmet and bikes. A simple electrical wire is needed to be embedded inside the strap of helmet and in between the cushion and alloy of helmet as depicted in Fig. 1 by red color. This small modification is required to be done by the helmet manufacturers to make it electronically anti-theft, just a simple electric wire needs to be embedded in it. Inside the bikes some modifications are required a socket (connecter) is to be provided in which we could easily insert the plastic part of strap in it, that connecter could be located on bike anywhere either under the seat or anywhere on dashboard which may not alter the beauty or style of bike, to be decided by bike designers.

\subsection{Electronic Alarm}

A relay switch and an electronic alarm [7] are needed, when the connectivity will be lost the controller will send signal to relay which will connect the horn to the battery of the bike.

\subsection{GSM Module}

A GSM module is used to send message to the owner if any suspicious activity is detected and also to monitor health status of the bike. GSM TTL UART [9] module is used in our prototype. It is built with Dual band GSM /GPRS (Global packet for radio services) engine sim900, works on frequencies 900/1800 Mhz [9].

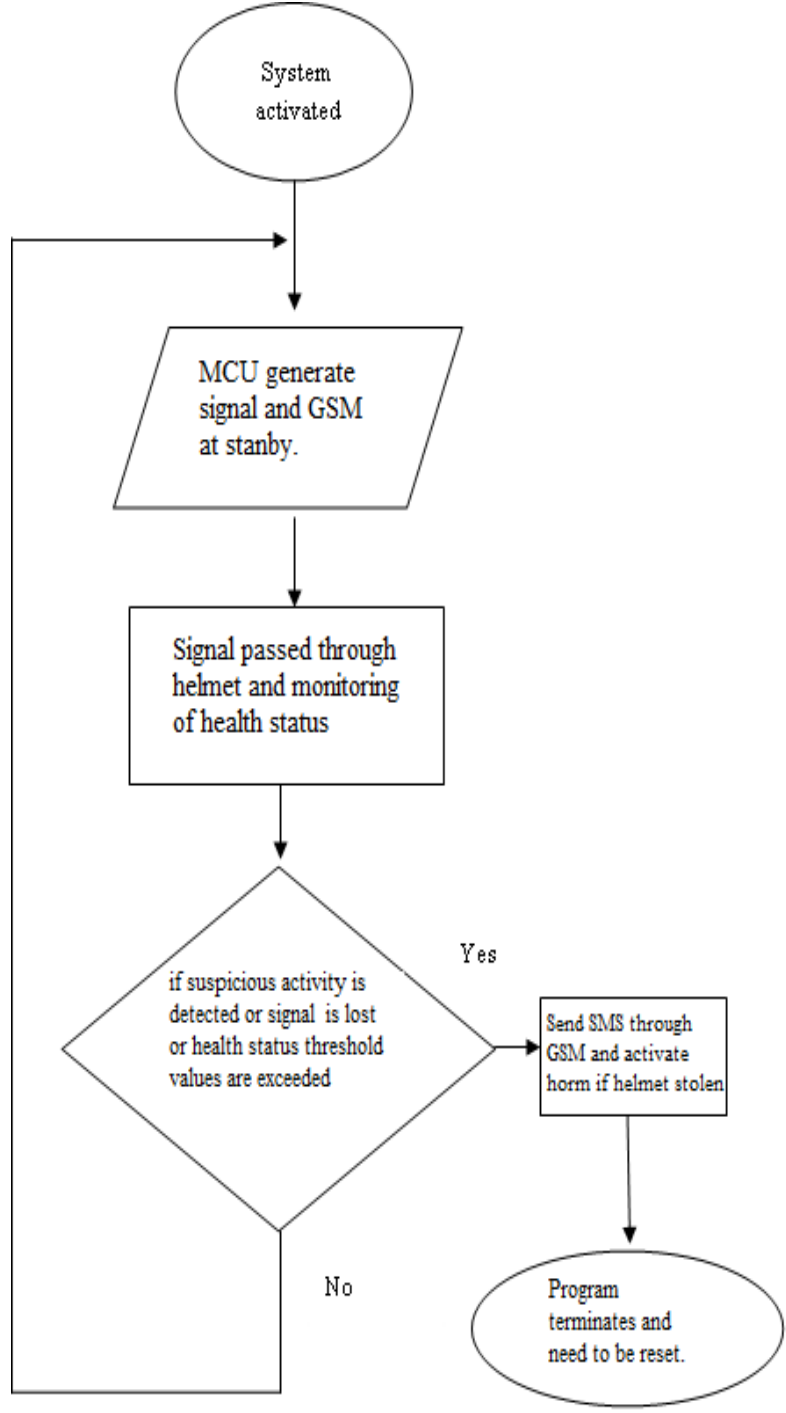

Fig 2. Basic Flow of Code

\section{SFTWARE/CODE}

In this section, the software for the system is discussed. The software has to do two functions primarily, first is to check the condition of the helmet and other is to continuously monitor the health status of the bike and send updates to the owner if required. A basic flow of the software is shown in Fig 2.The code will run infinitely times, once it is started.

Firstly the system is activated. The MCU (Micro controller unit) starts generating the signal which is transmitted through the strap of the helmet via the socket, the socket is used to connect the helmet strap with the circuit of the bike. In the meantime the GMS module is also made in standby position. The health status of the bike is monitored continuously after regular interval of time. Threshold values for different conditions like engine oil condition, battery health and 
engine health is already stored inside the program which may vary from bike to bike, and should be set after consulting its manufacturer. On account of lost of signal or the threshold values are exceeded for the health, the GSM module comes in active mode from standby mode. After coming in standby mode a short message is sent to the owner. The text message received by the owner will be of two formats. First format will be on account of helmet theft, the message will be as follows-

\section{"Dear Owner}

Suspicious activity detected on your vehicle no XXXX YYYY, your helmet security is at risk, please take immediate action."

Following text has two dynamic variables in it, first is the owner name which can be changed to the actual owner names when the system is being installed and secondly the vehicle number which can be changed to the actual vehicle registration number when the system is being installed. Inside the code an interrupt is made, on account of helmet theft not only GSM module will send a message to the owner but it will also put $\mathrm{ON}$ a electronic alarm. An electronic alarm will be a horn which will make noise as soon as the signal is lost, so it can attract security person on the site of bike and the burglar can be caught red handed. The second format will be as follows for the health status of the bike-

\section{"Dear Owner}

Your vehicle no XXXX YYYY, has problem in engine oil/engine health/battery health, please take immediate action else health of bike will be compromised."

Now the above message has 3 dynamic variables which are underlined also, first two variables are same as described in earlier message. The third one will select only one of the issues or may select all it depends on the actual problem occurred. In this way the owner is updated immediately if any fault is found in the bike.

The third format will be for service update of bike-

"Dear Owner

Your vehicle no XXXX YYYY, service is due on DD/MM/YYYY."

The DD/MM/YYYY can be set in the system as per the requirements.

In this way the entire software of the system works infinitely if no suspicious activity is detected or the health status of the bike is compromised.

\section{PROTOTYPE IMPLEMENTATION}

The Prototype was developed using the ATmega 16.Manually an electrical wire was embedded inside the strap of the helmet. The strap of the helmet was connected to the connector mounted on the prototype board. The entire code was compiled in AVR Studio 5 [10] and was burned on the microcontroller using the
ISP (In circuit Programmer) burner [11] and Avrdude [12] software. When the strap of the helmet was removed from the connector the horn started making noise and GSM module was activated. The GSM module sent successfully an alert message to the desired number. Hence the system worked successfully. On account of removal of helmet by cutting its strap the system will automatically detect the loss of helmet and will immediately make a noise. This noise will attract the Security guards on the site of theft. For the health status of the bike certain threshold values were set inside the system for different conditions. A keypad was interfaced with the system to enter the values below and above the threshold to replicate the actual bike system. Because in actual scenario the system of the bike will also feed the implemented system with certain digital values for different conditions. Which will be looked against the stored threshold values and appropriate action will be taken as per the written program. After entering value above threshold value for a particular condition the GSM module sent the message to the owner for that condition only.

\section{RESULTS AND CONCLUSION}

The proposed system when implemented with a prototype worked successfully as mentioned in the prototype implementation. The entire system can also be used for monitoring the health status of the bike. This will act as a remainder to the owner regarding the condition of bike from time to time on periodic basis. The proposed up gradation in the next version of this system are as follows. A GSM module in real time may also be used to track down the location of the bike on account of its theft. It can also be used for communication purpose, to get weather updates, to get the traffic updates of a particular location of an area. All this data can be used by the rider for a pleasant drive. The entire system is cost effective and very cheap as compared to any electronic lock system available in the market. The main charm of the present scheme is that the bike \& Helmet will not be treated as a separate entity.

When asked for a review from a group of students regarding the system, they were very much excited to buy this technology for their bikes as it will less up their tension regarding the safety of the helmet and is also very cost effective. This feedback is shown in table 1 200 people for each group were selected randomly. All the people were explained about the application of system and its usefulness. system will cost around \$20$\$ 25$ on their pockets-

\begin{tabular}{|l|c|c|c|c|}
\hline $\begin{array}{l}\text { Age } \\
\text { Group }\end{array}$ & Yes & No & May be & $\begin{array}{c}\text { Success } \\
\%\end{array}$ \\
\hline $18-20$ & 196 out of 200 & 1 out of 200 & 3 out of 200 & 98 \\
\hline $21-25$ & 192 out of 200 & 4 out of 200 & 2 out of 200 & 96 \\
\hline $25+$ & 190 out of 200 & 2 out of 200 & 8 out of 200 & 95 \\
\hline
\end{tabular}

Table 1. 


\section{ACKNOWLEDGMENTS}

We are thankful to The Omnipotent GOD for making us able to do something. We express our gratitude to ECE Department, Graphic Era University for providing us research opportunities and their wholehearted support for such activities. We would also like to thank Dr. R C Joshi (Chancellor) of Graphic Era University for guiding in writing the paper. Finally, our acknowledgement cannot end without thanking the authors whose papers helped us in developing this system.

\section{REFERENCES}

[1] http://en.wikipedia.org/wiki/Helmet.

[2] What should you know about helmets- "http://www.msfusa.org/downloads/helmet_CSi.pdf"

[3] S Redl, M Weber, M Oliphant - 1998 - dl.acm.org publication- " Book, GSM and personal communication handbook $1^{\text {st }}$ Artech House, Inc. Norwood, MA, USA @11998 , ISBN:0890069573”

[4] Atmel Atmega 16 Datasheet can be accessed from "www.atmel.com/Images/doc2466.pdf".

[5] Paul R. Zimmerman, Tim R . Sass, Motorcycle Helmet Laws and Motorcyclist Fatalities, November 2000, Volume 18, Issue 3, pp 195-215, Journal of Regulatory Economics, can be accessed from "http://link.springer.com/article/10.1023/A\%3A100 8124703161"

[6] Prof. F. T. McDermott M.D., Helmet efficacy in the prevention of bicyclist head injuries: Royal Australasian college of surgeons initiatives in the introduction of compulsory safety helmet wearing in Victoria, Australia, May/June 1992, Volume 16, Issue 3, pp 379-383, World Journal of Surgery, can be accessed from"http://link.springer.com/article/10.1007/BF021044 $35 "$

[7] Schmetter, RonaldM. Affiliation: Motorola Inc. Franklin Park, IL. "The piezoelectric loudspeakers: Its use in Audio System", AES E-Library, AES Convention:43 (September 1972) Paper Number:876

[8] Atmel ATiny 2313 datasheet, can be accessed from http://www.atmel.com/Images/doc2543.pdf

[9] GSM/GPRS TTL UART Modem Sim 900- details can be accessed from online store http://www.rhydolabz.com/index.php?main_page= product_info\&cPath $=122 \&$ products_id $=1080$ Manufacturer Rhydo labz.

[10] AVR Studio 5 tutorials can be accessed from"www.avr-tutorials.com/avr-studio-5/avr-studio-5" and"http://cs.slu.edu/ fritts/csci305/AVR/AVRstud ioTutorial.pdf"

[11] Lin Ling, I Meng,Li Gang(School of Precision Instrument and Optoelectronic Engineering, Tianjin University, Tianjin 300072,China) A MCU multifunction training platform based on ISP technology.

[12] AVR DUDE tutorials can be accessed from"http://www.ladyada.net/learn/avr/avrdude.html" 